\title{
A organização baseada no conhecimento: novas estruturas, estratégias e redes de relacionamento
}

\author{
Adroaldo Rossetti \\ Doutorando do Programa de Pós-Graduação em Engenharia e Gestão do \\ Conhecimento, da Universidade Federal de Santa Catarina (UFSC). \\ Pesquisador Embrapa Agroindústria Tropical. \\ E-mail: adroaldo@cnpat.embrapa.br \\ Ana Paula Reusing Pacheco \\ Doutoranda do Programa de Pós-Graduação em Engenharia e Gestão do \\ Conhecimento (UFSC). Professora Universidade do Sul de Santa Catarina - UNISUL. \\ E-mail: anapaula@unisul.br

\section{Bertholdo Salles} \\ Doutorando do Programa de Pós-Graduação em Engenharia e Gestão do \\ Conhecimento (UFSC). \\ E-mail: bertho@brturbo.com

\section{Marcos Garcia} \\ Doutorando do Programa de Pós-Graduação em Engenharia de Produção (UFSC). \\ E-mail:mgarcia@egc.ufsc.br

\section{Neri Santos} \\ Doutor em Ergonomie de l'Ingenierie pelo Conservatoire National des Arts et \\ Metiers, de Paris. Professor da Universidade Federal de Santa Catarina. \\ E-mail: neri@egc.ufsc.br
}

\section{Resumo}

0 objetivo deste artigo é apresentar uma abordagem de como 0 conhecimento está ensejando rápidas mudanças nas organizações, em suas estruturas, nas estratégias de negócios, nas formas de gestão e redes de relacionamento, fazer uma contextualização da nova sociedade do conhecimento e propor um modelo de organização com infra-estrutura baseada em conhecimento.

\section{Palavras-chave}

Organizações da era do conhecimento. Gestão do conhecimento. Estruturas organizacionais. Estratégias. Redes de relacionamento.

\section{The knowledge-based organization: new structures, strategies and relationship net}

\section{Abstract}

The objective of this paper is to present an approach on how knowledge has made the organizations change fast in their structures, business strategies, way of management and relationship nets, as well as to present a context of the new knowledge society and propose an organizational model with knowledge-based infrastructure.

\section{Keywords}

Knowledge organizations. Knowledge management. Organizational structures. Strategies. Relationship nets.

\section{INTRODUÇÃO}

As mudanças que vêm ocorrendo na sociedade do conhecimento, em que grande volume de informações é veiculado livremente por diversos meios, estão levando as organizações a refletir sobre que estratégias devem ser adotadas para continuar sobrevivendo com sucesso no mundo competitivo no qual a informação e o conhecimento são os bens de maior valor. Nesse contexto, novas redes de inovação e conhecimento são criadas, com papel importante na sobrevivência e no crescimento das organizações. Nesse cenário, segundo Tuomi (2001), as carreiras de trabalho de longa vida estão se transformando num mosaico em que trabalho produtivo, aprendizado e desenvolvimento de competências são inseparáveis.

Conforme Tapscott e Williams (2007), antigamente, nas organizações, o empregado era destinado a uma equipe empresarial e lá ficava. Construía laços de confiança e lealdade que lhe permitiam colaborar com seus colegas de maneira eficaz. Hoje, novas formas de colaboração em massa sugerem que as organizações podem obter maior êxito com uma abordagem mais auto-organizada com a formação de equipes, trabalhando em rede. Os autores opinam que as relações de emprego se tornarão necessariamente mais fluidas, definitivamente menos longas e certamente mais horizontais. Muitos funcionários gostarão disso à medida que procurarem flexibilidade, identidade, propriedade e aprendizado contínuo, tanto no local de trabalho quanto com seus colaboradores.

Para Katz et al., (2000), trabalhar em rede é um processo que consiste em organizar e manter colaborações eficientes. Portanto, deve ser alvo de muita atenção, com o objetivo de acessar idéias, tecnologias e compartilhar informações, experiências, conhecimentos técnicos e negócios entre organizações, institutos ou centros de pesquisa tecnológica e universidades. Para os autores, a base do trabalho em rede é mais a confiança entre os "sócios" que a firmação de contratos legais, ainda que na prática os contratos sejam utilizados em forma de acordos de colaboração. Para eles, o trabalho em rede não se organiza de maneira tradicional ou "vertical", seguindo os princípios de uma cadeia de suprimento (isto é, fazendo pedidos de bens ou serviços), nem usando contratados ou subcontratados. Ao contrário, o trabalho em rede se 
organiza em torno de processos de colaboração "horizontais" mais que "verticais". Finalmente, para formar redes eficazes, as organizações devem identificar as principais razões que têm para trabalhar em rede e centrar-se em atividades essenciais.

Nessa conjuntura, em que o sucesso do negócio está ficando cada vez mais dependente da inovação e do conhecimento, redes informais e redes de negócios estão sendo amplamente concebidas e se tornando essenciais em estruturas organizacionais e entre organizações. Para Tapscott e Williams (2007), as redes de negócios são baseadas em um novo tipo de colaboração entre instituições. As organizações inteligentes vêm utilizando esse potencial para desenvolver novos e poderosos modelos de negócios e sistemas. Elas não são apenas uma alternativa refinada para a velha grande organização. Para os autores, o surgimento das redes de negócios não significa que as organizações nunca vão se integrar verticalmente, movendo conhecimento e competências dentro dos seus limites. Cada organização precisa constantemente ajustar os próprios limites para satisfazer às exigências e oportunidades em constante mutação. Isso significa que as decisões sobre limites estão no bojo da estratégia de negócios. Isto é, quais competências devem ficar dentro e quais devem ficar fora? Ao se colaborar em uma rede de negócios, como serão divididas as recompensas? Como se pode garantir que se vai colher a nossa parte do valor?

Perante o exposto, fica evidente que os modos tradicionais de administrar as organizações se revelam inadequados e novas formas de gestão estão emergindo. Isso tem implicações no design organizacional, na estratégia, nas práticas de gestão e tecnologias organizacionais, conduzindo às novas teorias e práticas de gestão do conhecimento. O conhecimento, portanto, torna-se fator-chave na teoria econômica atual. Isso muda, conforme Carnoy (2000), as percepções e os sistemas de avaliação que estão por trás do comportamento econômico. Além disso, tem implicações fundamentais na realidade cotidiana material e mental das pessoas.

Diante desse quadro, a gestão do conhecimento parece ser o fator de sucesso das organizações de conhecimento intensivo, o desafio de buscar o equilíbrio entre o tecnológico e a evolução/ preservação do humano, na organização e em seu entorno. O objetivo deste artigo é apresentar uma abordagem de como o conhecimento está ensejando rápidas mudanças nas organizações, em suas estruturas e estratégias de negócios, nas formas de gestão e redes de relacionamento, fazer uma contextualização da nova sociedade do conhecimento e propor um modelo de organização com infra-estrutura baseada em conhecimento.

\section{REVISÃO DE LITERATURA}

Para Chesnais (1997) e Motta (1998), os efeitos da globalização têm suscitado um novo modo de funcionamento sistêmico do capitalismo mundial ou de uma nova modalidade do regime e de acumulação. Nesse panorama, o crescimento da sociedade do consumo e as transformações sociais dominam a sociedade atual e mudam profundamente a vida das pessoas e a produção de bens. É uma revolução impulsionada pelo conhecimento que atinge a todos os setores, exigindo mudanças estratégicas e estruturais envolvendo diretamente a gestão das organizações e suas formas de relacionamento, para se adaptarem a tais transformações.

No contexto da gestão, é necessário, segundo Terra (2001), discutir diversos aspectos, como o papel da alta gerência, por exemplo; novas práticas de organização do trabalho; desenvolvimento de processos específicos, para facilitar as práticas e políticas de gestão de recursos humanos; novas tecnologias de informação e comunicação e o relacionamento com os ambientes interno e externo. Esse novo modelo de gestão, chamado gestão do conhecimento, deve ser apoiado por uma infra-estrutura adequada, na qual exista, por exemplo, um centro para negócios de conhecimento (Center for Business Knowledge - CBK), conforme sugerem Ezingeard et al. (2000), adaptado, é óbvio, aos objetivos da organização.

Diante do exposto, antes de iniciar a discussão sobre a nova organização baseada no conhecimento, parece válido rever alguns conceitos, embora amplamente conhecidos, como informação e conhecimento, visto que muitos estudiosos lhes atribuem diferentes significados.

Angeloni (2003a, p.3) define a informação como "dados processados e contextualizados" e também como "um conjunto de dados selecionados e agrupados segundo um critério lógico para a consecução de um determinado objetivo" (ANGELONI, 2003b, p. XV). Apesar de ser o insumo para a geração do conhecimento, na visão de Sveiby (2003) é considerada como algo de pouco valor.

O conhecimento, por sua vez, é a informação contextualizada, com significado e interpretada, afirma Davenport e Prusak (1998). É, portanto, a informação já processada pelas pessoas, na visão de Angeloni (2003a), sendo intangível, invisível e difícil de imitar, complementam Terra e Angeloni (2003). Isso significa que o conhecimento é gerado a partir da informação, por meio da aplicação de modelos mentais e processos de aprendizagem das pessoas. É, portanto, intrínseco ao ser humano, sendo relacionado à ação, como afirmam Nonaka \& Takeuchi (1997), e associado à intuição, à experiência e aos valores.

Para Jarrar (2002, p.322),

conhecimento é informação combinada com experiência, contexto, interpretação e reflexão. É uma forma de informação de alto valor que está pronta para aplicar a ações e decisões. "Neste contexto, gestão do conhecimento 
significa "estratégias e processos de identificação, captura, e alavancagem do conhecimento para ajudar a empresa a competir".

\section{E continua afirmando que}

em geral, gestão do conhecimento é o processo de administrar continuamente conhecimento de todos os tipos, descobrir necessidades existentes e emergentes, identificar, explorar o conhecimento existente, adquirir ativos de conhecimento e desenvolver novas oportunidades.

\section{A organização baseada no conhecimento}

No momento presente, o mundo convive com a sociedade do conhecimento. As mudanças e as inovações tecnológicas estão ocorrendo em ritmo tão acelerado, que, além dos fatores tradicionais de produção, é fundamental identificar e gerir inteligentemente o conhecimento das pessoas nas organizações. Essa revolução tecnológica trazida pela globalização leva à transformação decisiva da sociedade e ao acirramento dos mercados internacionais. Conseqüentemente, as organizações se vêem forçadas a empreender esforços continuados de modernização organizacional, a fim de se manterem competitivas, adaptadas às características da nova sociedade.

Nesse sentido, segundo Katz et al. (2000), a realidade competitiva impõe formas de organização que privilegiem a comunicação e a integração entre os diversos subsistemas (social, técnico, informação e conhecimento, pesquisa e desenvolvimento, controle e tomada de decisão), processos, tecnologias, recursos financeiros e outros. Dentre esses, os autores destacam o subsistema social, que compreende as pessoas, com suas características fisiológicas e psicológicas, seus níveis de qualificação (formação e experiência), suas relações sociais dentro da organização e as condições organizacionais do trabalho. E o subsistema técnico, que compreende as tarefas a serem realizadas e as condições técnicas para a sua realização, envolvendo o ambiente de trabalho, as instalações, as máquinas, os equipamentos, as ferramentas e os procedimentos e normas operacionais, inclusive as condicionantes temporais para cada operação.

Nesse contexto, a flexibilidade e a capacidade de ação organizacional proativa, diante dos sobressaltos das mudanças e inovações, tornam-se imprescindíveis para a sobrevivência das organizações. Em um ambiente competitivo e turbulento, isso implica uma dinâmica complexa e incessante, que represente vantagem competitiva. Essas adaptações impactam na forma de organização do trabalho, em que as equipes possuem papel fundamental na flexibilização da organização e a competência das pessoas é fator-chave de sucesso.

Vários autores, entre os quais Katz et al., (2000), destacam o valor do trabalho em equipe para a gestão do conhecimento.
Ressaltam que o trabalho em equipe está relacionado com os modos de explorar a base de conhecimento da organização e de se desenvolver estrategicamente como uma "organização que aprende". Realçam a vantagem de tomar decisões e de empreender ações que normalmente são mais independentes e com maior autocontrole. As responsabilidades e os compromissos são bem definidos e a relação de lealdade, em geral, é muito bem estabelecida. Enfatizam, porém, a importância de se trabalhar sempre com a equipe para melhorar cada vez mais os níveis de confiança, cooperação e compreensão. Nesse ambiente, as melhorias não se estendem apenas às tarefas a serem realizadas, mas sobretudo se configuram como forma de potencializar as vantagens das competências profissionais. Segundo os autores, a composição das equipes deve ser decidida analisando-se as competências profissionais das pessoas (conhecimentos, habilidades, qualificações e experiências) em função dos objetivos e metas da organização, das necessidades do projeto e das tarefas a serem realizadas.

Na opinião de Bhatt (2001), para capitalizar o conhecimento, no contexto da sua criação, validação, apresentação, distribuição e aplicação, uma organização deve ser rápida em equilibrar suas atividades de gestão do conhecimento. Esse equilíbrio, segundo o autor, geralmente requer mudanças na cultura organizacional, em tecnologias e em técnicas organizacionais. Ele menciona também que várias organizações acreditam que, focalizando exclusivamente em pessoas, tecnologias, ou técnicas, elas podem administrar o conhecimento. Entretanto, o foco exclusivo ou disjunto em pessoas, tecnologias ou técnicas não permite a uma organização sustentar suas vantagens competitivas. É necessária a interação entre tecnologia, técnicas e pessoas. Para o autor, essa ação conjunta, associada à criação de um ambiente, como "aprendizagem-por-fazer", é que permite que uma organização gerencie efetivamente seu conhecimento e crie condições para sustentar suas vantagens competitivas.

Observa-se, pois, que a gestão do conhecimento é fundamental na interação sociofuncional das pessoas e organizações, cuja recíproca é plenamente verdadeira. Do ponto de vista operacional, pode-se dizer que a gestão do conhecimento consiste em combinar o saber (explícito) e o saber fazer (tácito) nos processos, nos produtos e na organização, para a criação de valor. Para tanto, é necessário, segundo Sacomano Neto e Escrivão Filho (2000): (1) combinar as competências individuais e o conhecimento, para produzir valor; (2) implantar uma nova cultura que partilhe de boas práticas da sociedade do conhecimento e afete de maneira positiva as organizações, suas estruturas e redes de relacionamento; (3) direcionar o conhecimento para a organização, valorizando os ativos intelectuais na otimização do conhecimento disponível, incrementando a sua capacidade de uso, em cada contexto.

Perante esse imperativo de inovação, a gestão do conhecimento é essencial, visto ser, principalmente, uma abordagem sistêmica 
com dimensões: (1) estratégica - orientada para o negócio e para a criação de valor; (2) organizacional - orientada para o trabalho e para diversas comunidades; (3) instrumental orientada para a tecnologia de suporte e para métodos de capacitação, transferência e retenção do conhecimento; (4) humana - orientada para os aspectos psicossociais e culturais na partilha do conhecimento, em que é, principalmente, conforme Marx (1998), guiar pessoas e equipes.

Para vários autores, entre os quais Rossetti e Morales (2007), a gestão do conhecimento envolve o gerenciamento de ativos intangíveis de diferentes naturezas: pessoas, conhecimentos tácitos, explícitos, individuais, organizacionais e de redes. $\mathrm{E}$, também, conhecimentos estruturais, que servem de base tecnológica para a estocagem, a melhoria e o fluxo dos bens intangíveis. A gestão do conhecimento é, por assim dizer, a capacidade de lidar de forma criativa com as diferentes dimensões do conhecimento. Isso envolve a sua criação, a partir de dados, sua transformação em informações, e, a partir da análise dessas informações, sua transformação em conhecimento propriamente dito. A eficácia do conhecimento depende de sua contextualização, categorização, armazenamento, uso e disseminação, correção, compilação e reutilização. A gestão do conhecimento, segundo Kruglianskas e Terra (2003), complementa e aumenta outras iniciativas organizacionais. Entre tais iniciativas estão o gerenciamento total da qualidade, a reengenharia de processos e o aprendizado organizacional, proporcionando novo e urgente centro de atenção para sustentar a posição competitiva das organizações.

Segundo Correia e Sarmento (2003), o papel fundamental da gestão do conhecimento é o de transformar o conhecimento individual em conhecimento coletivo. Isto conseguido faz com que as organizações estejam aptas e, portanto, capacitadas para aprender a aprender, envolvendo todos os membros nesse processo. Esse papel só será exercido, conforme enfatizam Mülbert et al. (2002), se as organizações desenvolverem estruturas organizacionais apropriadas ao novo contexto, com características de descentralização, favorecimento à participação, à criatividade e à inovação.

Galbraith (1997) defende a idéia de que a inovação exige uma organização projetada para essa finalidade. Nessa estrutura, segundo ele, os processos, as recompensas e as pessoas precisam estar combinados de forma especial para criar uma organização inovadora, projetada para fazer algo pela primeira vez.

\section{Novas estruturas organizacionais baseadas no conhecimento}

Entre essas estruturas, Galbraith (1997) apresenta o que ele chama de Organização inovadora, (figura 1), na qual devem coexistir duas estruturas organizacionais - a operacional e a inovadora - cuja finalidade é favorecer a criação e a aplicação do conhecimento.
Cabe à estrutura inovadora conceber as idéias e à estrutura operacional implementá-las. Observam-se, nessa estrutura, os papéis de orquestrador, patrocinador e gerador de idéias. Cabe ao orquestrador, que se encontra no nível estratégico da organização, a proteção aos geradores de idéias, a promoção de oportunidades para testar as novas idéias e o incentivo/recompensa à criação do conhecimento, apoiando aqueles cujas idéias se revelem eficazes. É ele o responsável em fazer com que as idéias criadas na estrutura inovadora sejam integradas à estrutura operacional. Ao patrocinador, por sua vez, cabe emprestar sua autoridade e também os recursos que possui, para levar as idéias adiante. Os patrocinadores são, comumente, gerentes que se encontram no nível tático da organização. O gerador de idéias, normalmente, é uma pessoa do nível operacional. Coletivamente, esses três papéis (orquestrador, patrocinador e geradores de idéias) trabalham de maneira integrada nas chamadas reservas e constituem a estrutura da organização inovadora. $\mathrm{O}$ orquestrador e o patrocinador trabalham tanto na estrutura inovadora quanto na operacional. Os geradores de idéias somente trabalham na reserva organizacional (grupos de $P \& D$ ), totalmente dedicados à criação de novas idéias para futuros negócios. Quando finalizam seus projetos, voltam para suas funções na estrutura operacional. O termo reserva é usado aqui no sentido de reserva florestal, um lugar protegido, um paraíso de aprendizado seguro.

\section{Figura 1}

\section{Estrutura de uma organização inovadora}

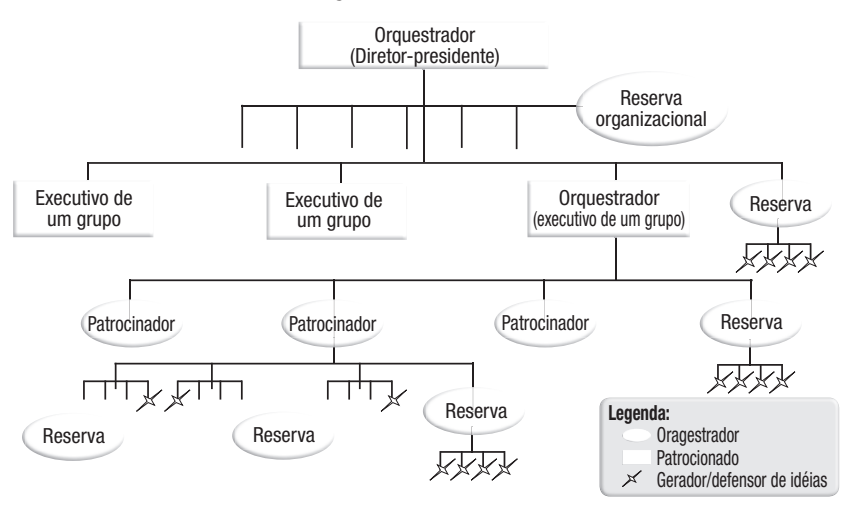

Fonte: Galbraith (1997).

Mais necessário até do que a importância estratégica da inovação é saber o que e como fazer para inovar e, também, sobre como usar melhor a infra-estrutura existente na organização. Sbragia et al., (2006) enfatizam que mesmo dentro da organização a inovação não ocorre por acaso. Ela precisa ser estimulada e ter um órgão que os autores chamam de unidade de pesquisa e desenvolvimento, que deflagre essa cultura inovativa. Essa tarefa terá tanto sucesso quanto for executada por trabalhadores do conhecimento, entre os quais, como enfatizam Iacono e Nagano (2007), a confiança, a cooperação e a capacidade de inovação, apresentem elevado grau de visibilidade. É fundamental que essas qualidades devam ser vivenciadas por todos os membros da cadeia envolvidos nesse processo. Os autores ressaltam que esse tipo de cooperação normalmente ocorre entre executivos 
de organizações inovadoras que fazem dessa relação um meio para obter vantagens competitivas.

Isso é tão importante, que Davenport (2006) chega a afirmar que os trabalhadores do conhecimento são responsáveis por incentivar a inovação e o crescimento das organizações, isto é:

São os que inventam os novos produtos e serviços, desenvolvem programas de marketing e criam as estratégias. $\mathrm{Na}$ economia atual, são os cavalos que puxam o arado do progresso econômico. Se as empresas se tornarem mais lucrativas, se as estratégias forem bem-sucedidas e se houver avanços na sociedade - a razão de tudo isso terá sido o aumento na produtividade e na eficiência dos trabalhadores do conhecimento (DAVENPORT, 2006, p.3).

Além disso, mesmo que as organizações tenham possibilidade e oportunidade de investir mais em inovação, a partir de uma cultura interna, nenhum sistema de inovação tecnológica amadurecerá sem a construção de uma interface sólida entre os setores privados e acadêmicos.

Para Kilmann (1997), as organizações contemporâneas se defrontam com ambientes progressivamente dinâmicos, que trazem problemas cada vez mais complexos e indefinidos. Isso requer das organizações uma estrutura capaz de enfrentar essa realidade de forma eficaz, preservando a competitividade no mercado. Para tanto, o autor apresentou uma estrutura organizacional denominada Organização colateral, cuja finalidade é resolver problemas complexos, não rotineiros e de longo prazo. Tais problemas, segundo o autor, incluem que novos mercados devem ser explorados; que novas tecnologias devem e podem ser desenvolvidas; que objetivos organizacionais devem ser revisados e alterados, como motivar mais eficazmente os funcionários, que políticas de responsabilidade social a empresa deveria formular e implementar. Essa estrutura, como a inovadora, mescla duas estruturas organizacionais - a operacional e a colateral (figura 2). A estrutura colateral é formada por pessoas de diversos níveis e departamentos da estrutura operacional. É, portanto, uma equipe multifuncional.

\section{Figura 2}

\section{Estrutura da organização colateral}

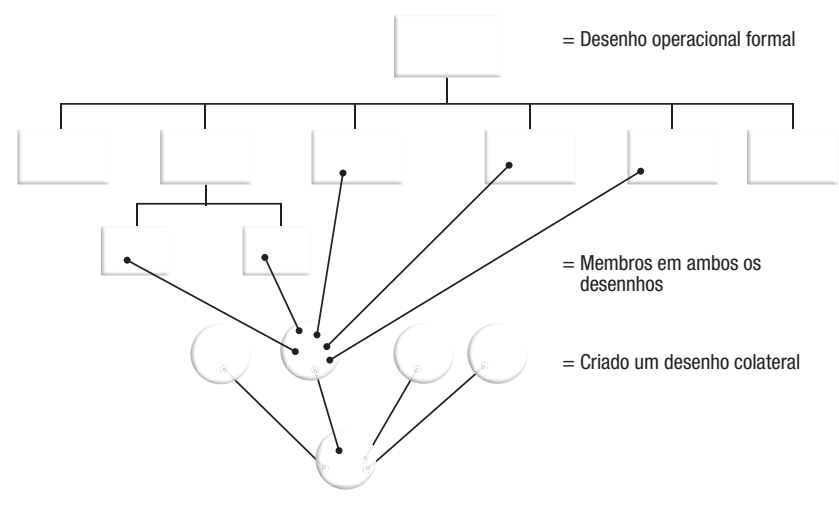

Fonte: Kilmann (1997).
Observa-se certa similaridade deste tipo de organização com a estrutura matricial, que combina a departamentalização por projetos (colateral) com algum critério tradicional de departamentalização (operacional), possuindo, portanto, multiplicidade de comando. Segundo mencionam Kilmann (1997) e Pacheco (2005), a estrutura matricial pode ser concebida de maneira intercalada. Nessa concepção, as pessoas dividem suas horas semanais de trabalho entre a estrutura tradicional e a por projetos ou contínua, em que as pessoas trabalham apenas na área de projeto até que este seja finalizado. Na organização colateral, as atividades são desenvolvidas apenas de maneira intercalada. A estrutura colateral está muito mais voltada para a criação e para a inovação, enquanto a departamentalização por projetos está mais voltada à solução de problemas e às necessidades mais específicas.

Figura 3

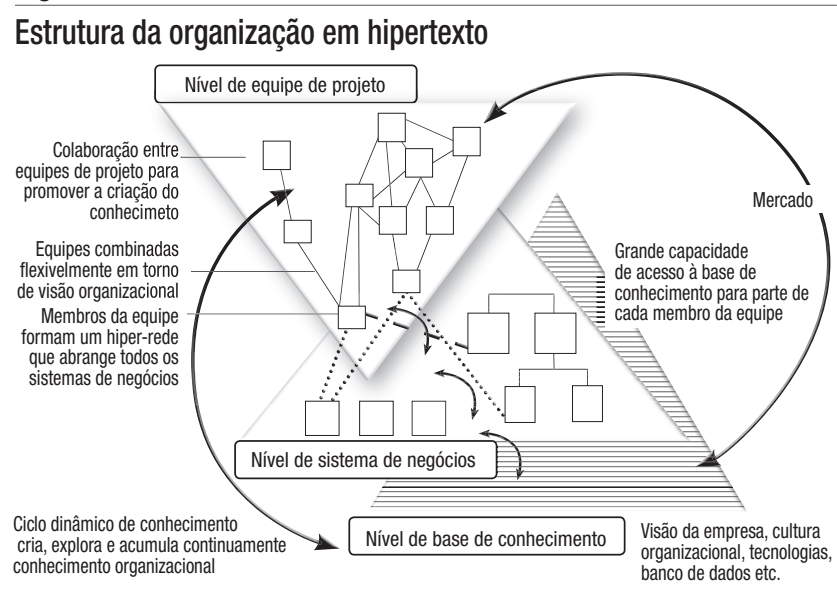

Fonte: Nonaka e Takeuchi (1997).

Kilmann (1997) propõe o funcionamento da organização colateral como um ciclo contínuo, que intercala a estrutura operacional e a colateral, voltada para (1) sentir o problema (estrutura operacional); (2) definir esse problema (estrutura operacional); (3) desenvolver soluções (estrutura colateral); (4) implementar as soluções encontradas (estrutura operacional).

Nonaka e Takeuchi (1997) apresentam a chamada Organização em hipertexto, cuja estrutura organizacional, da mesma forma que as duas organizações anteriores, está voltada para a inovação. Permite explorar, compartilhar, acumular e criar conhecimento de maneira contínua, repetida e em um processo em espiral. A organização em hipertexto possui uma estrutura hierárquica formal (figura 3 , a seguir), que funciona em conjunto com uma estrutura não hierárquica e auto-organizada, constituída de níveis interconectados, nos contextos de sistemas de negócios, de equipe de projeto e de base de conhecimento. Os autores propõem o funcionamento da organização em hipertexto como um ciclo dinâmico que atravessa os três níveis básicos da gestão do conhecimento: (1) criação do conhecimento (equipe de projeto) a partir da direção da alta gerência; (2) recategorização e recontextualização do conhecimento criado (base do conhecimento); e (3) desenvolvimento de atividades operacionais (sistema de negócios). 
Essa forma de negócios constitui a estrutura burocrática e corresponde ao nível central. Já a equipe de projeto (força-tarefa) encontra-se em um nível superior (pode haver várias equipes de projeto) e é voltada à criação do conhecimento. Essas pessoas são provenientes do sistema de negócios e, diferentemente da organização colateral, trabalham de forma contínua na equipe de projeto. A base do conhecimento, por sua vez, encontra-se em nível mais baixo e tem a finalidade de recategorizar e recontextualizar o conhecimento que é gerado nos outros dois contextos. Está incorporada à visão, à cultura e à tecnologia organizacionais. É aí que o conhecimento é armazenado e transformado em algo útil e significativo para a organização. A estrutura burocrática (sistema de negócios) utiliza-se da internalização e da combinação para implementar, explorar e acumular o conhecimento. Já a estrutura força-tarefa (equipe de projeto) faz uso da socialização e da externalização para a geração do novo conhecimento.

Apesar da crescente discussão sobre as novas estruturas organizacionais baseadas no conhecimento, cabe ressaltar que, para que uma organização se insira na economia do conhecimento, independentemente de sua estrutura é necessário que ela utilize adequadamente seus recursos intelectuais. Para Ostrom (1990), o capital intelectual é um dos ativos de conhecimento ou ativos intangíveis mais importantes numa organização, pois favorece a uma coletividade social a capacidade de aprender. Esse aprendizado, segundo o autor, envolve o conhecimento consciente, referente aos fatos e conceitos que podem ser estocados e recuperados da memória (conhecimento explícito individual); o conhecimento automático, referente às habilidades (conhecimento tácito individual); o conhecimento objetivo, aquele que é explicitado e que está disponível para a comunidade (conhecimento explícito social); e o conhecimento referente às rotinas organizacionais (conhecimento tácito social).

Sveiby (2003) aborda o assunto de forma análoga, mencionando que o capital intelectual engloba o capital humano, isto é, as competências das pessoas na organização, trabalhando individualmente ou em equipes. O capital estrutural, referente à infra-estrutura organizacional, incluindo tecnologias e processos que não dependem do staff chave. O capital de clientes refere-se ao relacionamento com clientes, fornecedores, distribuidores, parceiros, membros aliados, acadêmicos, órgãos reguladores e outros, tais como imagem organizacional e marcas. Compreender esse mecanismo é fundamental para que se estabeleça interação adequada desses recursos e se possa usufruir eficazmente as vantagens que eles oferecem. Isto significa identificar, codificar, compartilhar, usar e reutilizar; criar a partir de e abandonar os conhecimentos adequadamente. Para que isso se faça com eficiência, o CIKM (2003) indica o estabelecimento de um escritório de gestão do conhecimento (Knowledge Management Office - KMO) como elemento essencial para a obtenção da integração e alinhamento centralizado da gestão do conhecimento interdepartamental na organização.
As funções do $\mathrm{KMO}$ (figura 4, a seguir) abrangem implementação, suporte e refinamento do programa de gestão do conhecimento. $\mathrm{O}$ desempenho dessas funções deve ser amparado por uma estrutura paralela à estrutura burocrática da organização (figura 5), conforme a estrutura sugerida pelo CIKM (2003), com alguns membros permanentes.

O escritório de gestão do conhecimento (KMO) requer a função de um chefe, ocupado com os ciclos decisórios: humanos e empresariais focado na gestão e no relato dos recursos intelectuais. Dominando a visão, as metas e os índices gerenciais da gestão, o chefe do escritório de gestão do conhecimento assume os papéis de definições de padrões, normas, requerimentos ou outras necessárias aos programas. Questões relativas à implantação do programa são assumidas por um departamento responsável por tecnologias da informação e comunicação.

\section{Figura 4}

\section{Estrutura funcional do escritório de gestão do conhecimento (KMO).}

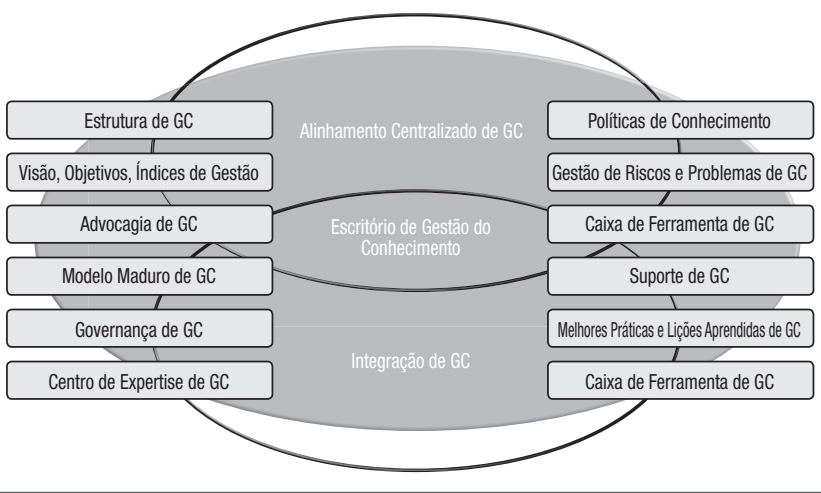

Fonte: CIKM - Instituto de Gestão do Conhecimento do Canadá (2003). Tradução dos autores.

Pessoas com reconhecido domínio em suas áreas de conhecimento e que almejam papéis de liderança devem, segundo o CIKM (2003), operar como "advogados" do programa (figura 5). Este papel e seu efetivo exercício têm importância vital na implantação da gestão do conhecimento, estimulando as discussões e encorajando os participantes das comunidades de prática a relatar suas opiniões sobre determinado problema a ser tratado.

Os chamados campeões e "homens-chave" (stakeholders) são, conforme o caso, de nível estratégico, ou organizacional, ou operacional.

Os comitês de condução (ou governança), necessários aos médios e grandes projetos, tratam da ligação e do envolvimento de todos os funcionários e departamentos da organização. Seus membros devem ser escolhidos cuidadosamente e serem pessoas respeitadas em suas áreas de atuação.

Engenheiros do conhecimento são analistas de negócios, cujo papel é sistematizar o fluxo de conhecimento num ciclo decisório. 
A comunicação é de extraordinária importância na implantação (projeto e desenvolvimento) de um programa de gestão do conhecimento, bem como para a reutilização dos recursos intelectuais, no escritório de gestão do conhecimento. Ela funciona como fator motivador da participação. Se adequada e competentemente executada, deve informar claramente os benefícios individuais e coletivos do programa de gestão do conhecimento.

A capacitação também é de fundamental importância no desenvolvimento do programa. No nível de informação, preocupa-se em divulgar as iniciativas, orientações, mapas de conhecimento, repositórios de conhecimento e a correta aplicação das ferramentas para, evitando a sobrecarga de informações, maximizar o seu uso. A capacitação de usuários, com base na retroalimentação dos "advogados" e patrocinadores do programa, atua nas necessidades específicas de departamentos ou indivíduos.

\section{Figura 5}

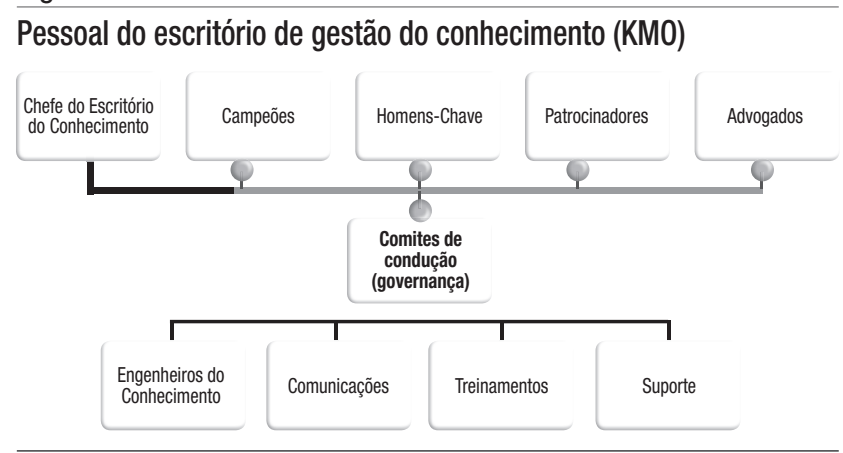

Fonte: CIKM - Instituto de Gestão do Conhecimento do Canadá (2003). Tradução dos autores.

Além dos vários arranjos organizacionais apresentados e das estratégias que antecedem e permeiam tais estruturas, a revolução impulsionada pelo conhecimento que atinge as organizações também impõe mudanças na forma de relacionamento das organizações, principalmente, por meio da formação de redes.

\section{Redes de relacionamento}

A formação de redes se dá pelo contato de pessoas e organizações com interesses similares, cujo propósito é descobrir oportunidades, compartilhar recursos, aprender melhores práticas, dar ou receber auxílio. As chamadas comunidades de prática, comunidades de especialistas, comunidades de práticos ou microcomunidades de conhecimento têm em comum a característica de envolver indivíduos que trocam informações, insights, experiências e ferramentas sobre alguma área de interesse comum.

As comunidades de prática, na visão do CIKM (2003), formalizam essas redes sociais e abrigam especialistas com disposição para compartilhar conhecimento. Podem se desenvolver horizontal ou verticalmente. Horizontalmente, agregam peritos em diversos temas de domínio dos vários departamentos da organização, possibilitando a melhoria da comunicação interdepartamental e dão ciência coletiva do que se passa em tais departamentos. Verticalmente, unem indivíduos com objetivos e metas comuns, sendo o processo decisório feito pela combinação das diversas contribuições de todos os membros da comunidade. As comunidades de prática formam substanciais bases de conhecimento de lições aprendidas, melhores práticas e experiências.

Em outro ângulo, Hustad (2004) denota que, embora mais complexas e de maiores riscos, as trocas entre comunidades com interesses distintos apresentam elevado potencial para criação de novos e relevantes conhecimentos. Para Jones et al. (1997), esses processos de troca devem seguir algumas regras de governança, a fim de que atendam à cultura organizacional, encoragem o efetivo desenvolvimento de conhecimento e fomentem a formação de equipes multifuncionais.

O conhecimento especializado é primeiramente distribuído, conforme Hawryszkiewycz (1999), seguindo-se as necessárias explicações e narrativas para capacitar as pessoas a construir significados e interpretar o conhecimento inserindo-o no seu próprio contexto. Além disso, Choo (2003) afirma que a busca consciente do preenchimento dessas "lacunas de conhecimento" pelo contato social é a essência da formação das redes de conhecimento. As redes de conhecimento podem ser criadas entre indivíduos de uma mesma organização; entre organizações com interesses comuns, independentemente de porte; entre organizações e institutos de conhecimento ou entre organizações globais. Boekhoudt e Van Der Sappen (2004) mostram como pequenas organizações podem se organizar entre si, por similaridade de objetivos, e com instituições de conhecimento (universidades, institutos de pesquisa e desenvolvimento e outras), e formar redes de conhecimento. Esse procedimento lhes facilita, principalmente, o acesso às inovações tecnológicas e à própria formação de comunidades de prática, com quantidade e qualidade relevantes de peritos. De outra forma, pelo pequeno porte, muitas pequenas e médias organizações não teriam condições práticas de formar tais redes e estariam alijadas do processo de criação e gestão do conhecimento.

Na formação de redes ou comunidades em âmbito global, Hustad (2004) considera que as particularidades locais como cultura, contexto, ambiente e outras devem ser observadas, especialmente no estabelecimento de políticas centralizadas para gestão do conhecimento, isto é:

Em teoria social do conhecimento, as organizações podem ser vistas como coletivos sociais e 'sistemas de conhecimento'; onde são enfatizados os quatro princípios do processo social do conhecimento: criação (ou construção), 
armazenamento/recuperação, transferência e aplicação. Organizações vistas como sistemas de conhecimento representam a natureza cognitiva e social do conhecimento organizacional e sua incorporação na prática e na cognição individuais, bem como na prática e cultura coletivas. (HUSTAD, 2004, p.58).

Nesse contexto, a formação de redes ou comunidades, pela estimulação da transferência de conhecimento, é um empreendimento significativo para a criação de novos conhecimentos.

Merece destaque, igualmente, o surgimento das "comunidades de cognição" em organizações intensivas de conhecimento. As "comunidades de cognição" ou "comunidades do saber", conforme designam Hustad (2004, p.59), consistem de "profissionais do conhecimento com habilidades especiais em certos tópicos". Em uma organização intensiva de conhecimento, a coexistência de múltiplas "comunidades de cognição" se complementam, de forma complexa e dinâmica. Com freqüência apresentam rica hierarquia de comunidades intra-organizacionais, interorganizacionais e entre organização e seu ambiente. Cabe ressaltar que as pessoas podem pertencer, simultaneamente, a várias comunidades, potencializando o conhecimento, pelo contato com temas diversos e o surgimento de novas configurações de conhecimento.

Com base na revisão bibliográfica, propõe-se, a seguir, um novo modelo de organização.

\section{PROPOSTA DE UM MODELO DE ORGANIZAÇÃO BASEADA NO CONHECIMENTO}

A estrutura de uma organização baseada no conhecimento deve ser caracterizada por instrumentos que viabilizem o conhecimento como o principal elo de negócios. É essencial que haja, nessa estrutura, um suporte sociotécnico tenaz, a partir da alta gerência, perpassando toda a organização, que aja como catalisador, para estimular a evolução da gestão do conhecimento. Tal apoio sociotécnico é indispensável tanto para implementar processos de gestão do conhecimento, como para criar um ambiente de conhecimento que sustente várias categorias de capacidades de gestão do conhecimento, pelo desdobramento dos recursos disponíveis na organização. $\mathrm{O}$ apoio sociotécnico contribui para aumentar a maturidade das práticas de gestão do conhecimento. Isso requer que o conhecimento, principal ativo da organização, seja permanentemente gerido nas suas diversas dimensões: criação, aquisição, validação, conversão, apresentação, compartilhamento, distribuição, aplicação, até sua incorporação à memória organizacional. Isso, além de constituir a principal fonte de uso eficaz do conhecimento, como forma de melhorar a competitividade organizacional, exige instrumentos que garantam a proteção do conhecimento organizacional. É imperativo, além disso, que se criem instrumentos que favoreçam, por exemplo: a) o estabelecimento de grupos temáticos. Esses grupos devem congregar profissionais do conhecimento, de mesma área, de áreas afins, ou até de áreas diferentes, que têm interesses comuns. Trabalham buscando soluções para problemas organizacionais, por meio de projetos ou outros meios, que eventualmente podem envolver conhecimentos de um, dois ou mais grupos ou até de outras organizações da rede de relacionamento. Em vista disso, trocam informações para apoio mútuo, no mesmo grupo, ou as buscam em outros grupos ou nas organizações da rede. Em face dessas características comuns, mantêm comunicação por vários meios: face a face, por e-mail, chats, e-groups e outras ferramentas de comunicação via Intranet ou Internet. É nesses grupos temáticos que ocorre por excelência a disseminação, o compartilhamento e a reutilização do conhecimento. A rigor, os grupos temáticos podem gerar um tipo especial de memória organizacional, pois seus membros vão formando uma cultura comum à medida que se relacionam. A conversão do conhecimento desses grupos em algo sistematizado depende da existência de hábeis profissionais do conhecimento para essa tarefa, da existência de um repositório de conhecimento bem estruturado e de ferramentas para sistematizar as informações e o conhecimento que circulam por seus integrantes, intra e entre grupos e pelas redes de organizações;

b) a formação dos grupos temáticos deve ser precedida da clara definição dos objetivos e propósitos da organização e de um mapeamento de suas competências. Essa atividade serve para identificar onde estão as habilidades e competências de cada indivíduo da organização - quem faz o quê, quem sabe o quê, quem é bom em que tipo de tarefa ou atividade. Por meio do mapeamento de competências é possível saber, não apenas onde estão os conhecimentos específicos, úteis à organização, mas em quais tipos de conhecimento a organização precisa ser fortalecida, por exemplo. Esse mapeamento de competências deve ser feito, também, em relação ao ambiente externo da organização, com relação aos indivíduos de sua rede de relacionamento: organizações, clientes, fornecedores e até competidores. O mapeamento de competência, da forma indicada, além de um suporte indispensável para o estabelecimento dos grupos temáticos, apóia a construção de padrões para a estruturação da memória organizacional.

Nesse modelo organizacional é fundamental a existência de um escritório de gestão do conhecimento (EGC) numa posição middle-up-down, entre a alta gerência e a área operacional. Um aspecto-chave nessa estrutura é como o conhecimento adquirido será acrescentado ao já existente. Deverá existir um processo de submissão do conhecimento para aperfeiçoamento, a partir do gerente do EGC, aos especialistas dos grupos temáticos, da área operacional, dos gerentes de redes. Quando necessário, deve passar também por discussão em um fórum que envolva especialistas dos diversos grupos e áreas, sendo 
regularmente revisto pelo EGC. É necessário que, ligado ao EGC, haja um suporte eficaz de tecnologia da informação, como instrumento efetivo de apoio à agilidade dos processos de gestão do conhecimento.

Esse modelo de organização aqui proposto deve ser embasado em uma cultura organizacional voltada ao conhecimento, que se não houver deve ser construída, a fim de facilitar, entre outras coisas, a definição de alguns tipos de papéis ou funções básicos, como:

- gerentes de conhecimento de unidades de negócios, que assegurem o desenvolvimento da gestão do conhecimento;

- gerentes de redes de conhecimento, que assegurem que a gestão do conhecimento sirva à direção estratégica do negócio a que pertence;

- secretários de rede, que facilitem o processo de gestão do conhecimento (são "mentes e corações" da gestão do conhecimento);

- gerentes de atribuição do conhecimento, que assegurem a atribuição e o estímulo ao processo de gestão do conhecimento;

- especialistas em matéria de negócios - pessoas especializadas em determinada área.

A figura 6 representa uma estrutura do modelo proposto.

Figura 6

Proposta de uma estrutura organizacional baseada no conhecimento

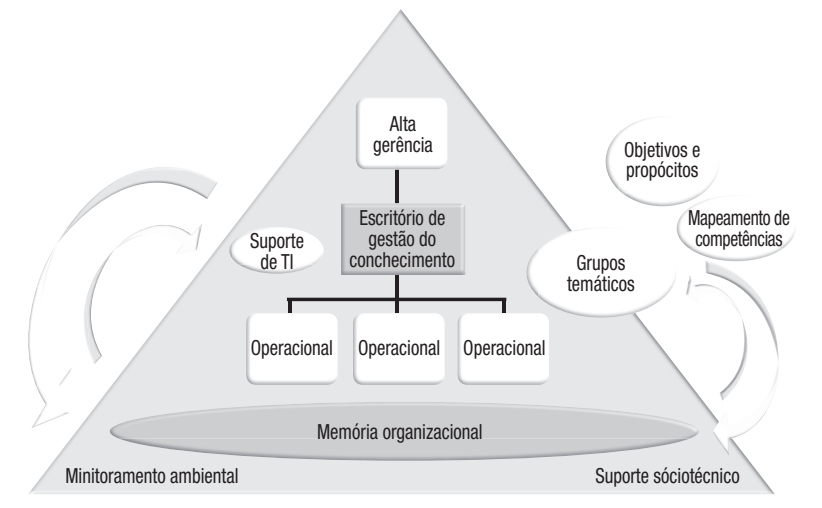

Fonte: elaborada pelos autores.

\section{CONSIDERAÇÕES FINAIS}

A partir de uma revisão de literatura, mostraram-se as mudanças que vêm ocorrendo na sociedade do conhecimento, como essas transformações e as estratégias baseadas em conhecimento afetam diretamente as estruturas organizacionais, levando ao desenvolvimento de novas modalidades de gestão e redes de relacionamento.
Diante dessa visão, o foco da gestão baseada em conhecimento parece ser mesmo a pessoa, com suas características fisiológicas, psicológicas, culturais e seus níveis de qualificação. A cultura talvez seja o fator mais influente na promoção ou inibição de práticas de gestão do conhecimento. Em face disso, torna-se relevante atentar às diferentes culturas da organização e/ ou dos atores das redes de trabalho, de maneira a permitir aos seus diversos componentes realizar seus objetivos. Isso impõe às gerências entender de aspectos ligados à etnia, culturas e línguas, de modo a capitalizar o conhecimento de todos os atores.

O papel das pessoas e da tecnologia na gestão do conhecimento é fundamental no projeto organizacional. Isso significa que as organizações são sistemas sociotécnicos, capazes de capturar as interconexões entre pessoas e tecnologia. Se, por exemplo, dois grupos devem colaborar de forma próxima, devido às exigências do projeto organizacional, é essencial que eles falem a mesma língua (figurativa e literalmente) e que a infra-estrutura técnica e as logísticas físicas facilitem a comunicação entre eles. Neste contexto, as pessoas não são apenas uma variável da gestão de mudanças a ser adicionada à equação na sua fase de execução. Ao contrário, suas necessidades, aspirações e valores são pré-requisitos do projeto organizacional e tão básicos quanto a sua viabilidade técnica e econômica. Além disso, tendo em vista que a contribuição intelectual está cada vez mais importante nas organizações, considerar o capital humano está se tornando, cada vez mais, central no projeto organizacional.

Nessa conjuntura, o trabalho em equipe tem singular significado, pois ajuda a instituir uma organização baseada na cooperação entre as pessoas; favorece mais rapidamente a inovação e o trabalho em rede. Tal é uma característica da filosofia contemporânea de gestão, que promove os valores do trabalho em equipe. Baseia-se no reconhecimento da necessidade de possuir qualidade, confiabilidade, flexibilidade e capacidade de resposta em todos os níveis da organização, em especial, em se conseguir que a organização ofereça um serviço que atenda às necessidades e expectativas de seus clientes.

Esse aspecto colaborativo do trabalho em equipe facilita a concepção das organizações segundo seus próprios processos, em vez de fazê-los conforme a especialização funcional. Algumas organizações vêem na formação de equipes de trabalho até uma maneira de reduzir os níveis de absenteísmo e rotação de pessoal, entre outros. Convém lembrar a importância das tecnologias de informação e comunicação, nesse contexto, como material estrutural para o projeto organizacional. Elas propiciam às arquiteturas organizacionais funcionar em rede intra-organizacional e multiorganizacionais, o que sem elas seria impossível.

Uma rede colaborativa, por sua vez, é desenvolvida como conseqüência de laços de confiança, comunicação produtiva, 
canais de decisão e um razoável limite permeável para definir os membros. O capital social é, fundamentalmente, baseado na confiança, normas e redes. A confiança desenvolve-se com o tempo, à medida que os indivíduos avaliam a confiabilidade uns dos outros, com uma série de interações. A chave da propriedade social da confiança é a transitividade, que permite que uma confiança generalizada se estabeleça em amplas redes, cujos membros não têm contato extensivo uns com os outros. A implementação do trabalho em rede depende das razões que as empresas têm para utilizá-lo.

Definidas tais razões, deve-se identificar organizações apropriadas quanto à complementaridade estratégica e vários outros aspectos, entre os quais: analisar e entender as capacidades existentes nas organizações (conhecimentos, habilidades, recursos, inclusive os tecnológicos, etc.). Isso ajuda a decidir como serão gerenciadas as relações do trabalho em rede; identificar os projetos de colaboração existentes; entender como serão explorados os resultados do trabalho em rede.

A era da inteligência em rede é promissora, cheia de oportunidades inimagináveis. Não se trata apenas da organização em rede da tecnologia, mas da organização em rede dos seres humanos por meio da tecnologia. Não se trata de uma era de máquinas inteligentes, mas de seres humanos que, usando inteligentemente as máquinas, através de redes, podem combinar a sua inteligência, conhecimento e criatividade

\section{REFERÊNCIAS}

ANGELONI, Maria Terezinha. Elementos intervenientes na tomada de decisão. Ciência da Informação, Brasília, v. 32, p. 17-22, 2003 a.

. Organizações do conhecimento: infra-estrutura, pessoas e tecnologia. São Paulo: Saraiva, 2003b.

BHATT, Ganesh D. Knowledge management in organizations: examining the interaction between technologies, techniques, and people. Journal of Knowledge Management, v. 5, n. 1, p. 68-75, 2001.

BOEKHOUDT, Piet; VAN DER STAPPEN, Petra. The aspect project case: a model for SME adoption of ICT innovation. In: INTERNATIONAL CONFERENCE ON ELECTRONIC COMMERCE - ICEC, 6., 2004, Delft. Proceedings... Nova York: ACM Press, 2004. V. 60, p. 201-206.

CANADIAN INSTITUTE OF KNOWLEDGE MANEGEMENT. A common KM framework for the Government of Canada: Frid Framework for enterprise knowledge management, version 3.0. Ottawa, 2003.

CARNOY, Martin. Sustaining the new economy: work, family and community in the information age. Cambridge, MA: Harvard University Press, 2000. para conseguir grandes avanços na criação de riqueza e de desenvolvimento social.

As redes podem mudar a inteligência de uma organização ao trazer know-how coletivo para a solução de problemas e para a inovação. Ao abrir os canais de comunicação humana, é possível que a consciência dos indivíduos seja estendida às organizações, pois, assim como as pessoas, as organizações também podem aprender. A partir da conscientização, as organizações podem se tornar capazes de aprender - e esse é um pré-requisito para a sobrevivência. A inteligência organizada em rede é o elo que falta no aprendizado organizacional e a organização consciente pode ser à base da fugaz organização capaz de aprender. E talvez a inteligência organizada em rede possa ser estendida para além das organizações, para criar um despertar mais amplo - a consciência social - em comunidades, nações etc.

Com base nessas considerações, propôs-se um modelo de organização com suporte em uma infra-estrutura de gestão do conhecimento, com a implantação de instrumentos que viabilizem a transformação das organizações em organizações intensivas de conhecimento.

Artigo submetido em11/09/2007

e aceito para publicação em 16/05/2008.
CHESNAIS, François. Novo capitalismo intensifica velhas formas de exploração. Folha de São Paulo, São Paulo, nov. 1997. Caderno Mais, p. 4.

CHOO, Chun Wei. A organização do conhecimento: como as organizações usam a informação para criar significado, construir conhecimento e tomar decisões. Tradução Eliana Rocha. São Paulo: Senac, 2003.

CORREIA, Ana Maria Ramalho; SARMENTO, Anabela. Knowledge Management: key competences and skills for innovation and competitiveness. In: TECHNOLOGY AND HUMAN RESOURCE MANAGEMENT INTERNATIONAL CONFERENCE ON THE DUAL INTERACTION BETWEEN TECHNOLOGY AND HUMAN RESOURCE, CERAM, 2003, Sophie Antipolis. Proceedings... Sophie Antipolis, 2003. p. 18-23.

DAVENPORT, Thomas H. Pense fora do quadrado: descubra e invista em seus talentos para maximizar resultados da sua empresa. Tradução Alessandra Mussi Araújo. Rio de Janeiro: Elsevier, 2006.

; PRUSAK, Laurence. Conhecimento empresarial: como as organizações gerenciam o seu capital intelectual. Tradução Lenke Peres. 8. ed. Rio de Janeiro: Campus, 1998. 
EZINGEARD, Jean-Noël; LEIGH, Simon; CHANDLER-WILDE, Rebbeca. Knowledge management at Ernst \& Young UK: getting value through knowledge flows. In: International Conference on Information Systems, 21., 2000, Brisbane. Proceedings... Atlanta: Association for Information Systems, 2000. p. 807-822.

GALBRAITH, Jay R. Projetando a organização inovadora. In: STARKEY, Ken (Ed.). Como as organizações aprendem: relatos do sucesso das grandes empresas. São Paulo: Futura, 1997. p. 190218.

HAWRYSZKIEWYCZ, Igor T. Knowledge sharing through workspace networks. In: ACM SIGCPR CONFERENCE ON COMPUTER PERSONNEL RESEARCH, 1999, Louisiana. Proceedings... Sydney: University of Technology, 1999. p. 79-85.

HUSTAD, Eli. Knowledge networking in global organizations: the transfer of knowledge. In: SIGMIS CONFERENCE ON COMPUTER PERSONNEL RESEARCH, 2004, Tucson. Proceedings... Norway: Agder University College, 2004. p. 55-64.

IACONO, Antonio; NAGANO, Marcelo Seido. Uma análise e reflexão sobre os principais instrumentos para o desenvolvimento sustentável dos arranjos produtivos locais no Brasil. Revista Gestão Industrial, Paraná, v. 3, n. 1, p. 37-51, 2007.

JARRAR, Yasar F. Knowledge management: learning for organizational experience. Managerial Auditing Journal, Melbourne, v. 17, n. 6, p. 322-328, 2002.

JONES, Candace T.; HESTERLY, William S.; BORGATTI, Stephen P. A general theory of network governance: exchange conditions and social mechanisms. Academy of Management Review, Atlanta, v. 22, n. 4, p. 911-945, Oct. 1997.

KATZ, Ralph et al. Organizations. In: DORF, Richard C. (Ed.). The technology management handbook. Boca Raton: CRC Press, 2000. Cap. 7.

KILMANN, Ralph H. Desenhando organizações colaterais. In: STARKEY, Ken (Ed.). Como as organizações aprendem: relatos do sucesso das grandes empresas. São Paulo: Futura, 1997. p. 219237.

KRUGLIANSKAS, Isak; TERRA, José Cláudio Cyrineu. Gestão do conhecimento em pequenas e médias empresas. São Paulo: Negócio, 2003.

MARX, Roberto. Trabalho em grupos e autonomia como instrumentos de competição. São Paulo: Atlas, 1998.

MOTTA, Fernando Cláudio Prestes. Teoria geral da administração: uma introdução. 19. ed. São Paulo: Pioneira, 1998.
MÜLBERT, Ana Luísa; MUSSI, Clarissa Carneiro; ANGELONI, Maria Terezinha. Estrutura: o desenho e o espírito das organizações. In: ANGELONI, Maria Terezinha. (Org.). Organizações do conhecimento: infra-estrutura, pessoas e tecnologia. 1. ed. São Paulo: Saraiva, 2002. v. 1, p. 62-78.

NONAKA, Ikujiro; TAKEUCHI, Hirotaka. Criação de conhecimento na empresa: como as empresas japonesas geram a dinâmica da inovação. Tradução Ana Beatriz Rodrigues; Priscilla Martins Celeste. 14. ed. Rio de Janeiro: Campus, 1997. 358p.

OSTROM, Elinor. Governing the commons: the evolution of institutions for collective action. New York: Cambridge University Press, 1990.

PACHECO, Ana Paula Reusing. Gestão estratégica de empresas de varejo e de serviços. 1. ed. Palhoça: UnisulVirtual, 2005. V. 1.

ROSSETTI, Adroaldo Guimarães; MORALES, Aran Bey Tcholakian. O papel da tecnologia da informação na gestão do conhecimento. Ciência da Informação, Brasília, v. 36, n. 1, p. 124 135, jan./abr. 2007.

SACOMANO NETO, Mário; ESCRIVÃO FILHO, Edmundo. Estrutura organizacional e equipes de trabalho: estudo da mudança organizacional em quatro grandes empresas industriais. Gestão $\mathcal{E}^{2}$ Produção, São Carlos, v. 7, n. 2, p. 136-145, ago. 2000.

SBRAGIA, Roberto (Coord.). Inovação: como vencer esse desafio empresarial. 1. ed. São Paulo: Clio, 2006.

SVEIBY, Karl Erik. A nova riqueza das organizações: gerenciando e avaliando patrimônios de conhecimento. 7. ed. Rio de Janeiro: Campus, 2003.

TAPSCOTT, Don; WILLIAMS, Anthony D. Wikinomics: como a colaboração em massa pode mudar o seu negócio. Tradução Marcello Lino. Rio de Janeiro: Nova Fronteira, 2007.

TERRA, José Cláudio Cyrineu. Gestão do conhecimento: o grande desafio empresarial. 2. ed. São Paulo: Negócio, 2001.

; ANGELONI, Maria Terezinha. Understanding the difference between information management and knowledge management. In: INTERNATIONAL CONFERENCE FOR THE INTERNATIONAL ASSOCIATION OF MANAGEMENT OF TECHNOLOGY, 12., 2003, Nancy. Proceedings ... Nancy, 2003.

TUOMI, Iikka. From periphery to center: emerging research topics on knowledge society. Technology Review, Helsinki, v. 16, p. 1-63, ago. 2001. 